\title{
Human Intrusion Detection Using Wi-Fi or ZigBee RF Signals
}

\author{
Ronak Gune \\ Department of Computer Engineering, RMD Sinhgad School of Engineering
}

\begin{abstract}
Wi-Fi is the wireless networking technology which allows two or more users to connect to each other or connect to the internet within a particular area. Wi-Fi thus enables a number of devices to communicate with each other using Radio Frequency signal which helps to use a lot of advanced services to be provided to the user. In the proposed system RF signals form Wi-Fi and ZigBee sensor nodes were used and the received signal strength indicators (RSSI) were used as a test to detect the presence of human beings in an indoor environment. This system can be used as an actual alarm for detection of physical intrusion in a certain area and also can be used to save energy and reduce costs on a large scale.
\end{abstract}

Keywords: Alarm; Intrusion Detection; RSSI;ZigBee; Wi-Fi.

\section{Introduction}

Intrusion detection in a certain given environment is one of the most important topics that we have to consider nowadays because of security issues and also for energy management.

The traditional security approaches include setting up lasers, cameras or even people for security measures. However, this may lead to wastage of resources like money, storage and power. Thus we need to come up with measures which use some different methods other than those available for better security purposes or energy management.

Wireless sensor networks can be considered as a good tool to monitor and stop events which can be harmful to man. Low cost sensors, radios and systems can help the development of sensor networks to help users in various environments and allow them to control such situations. Wireless sensor technology can be used in various fields such as medical, educational or military.

The presence of an intruder can be determined in an indoor environment using Received Signal Strength Indicator. The objective of the paper being reviewed [1] is to statistically characterise the Radio Frequency signal in an indoor environment and to determine if a human being present in the room is being detected. Irregularity in the strength of radio signals is a common phenomenon and is often considered as a disadvantage of radio networks. Irregularity in the signal strength is seen even more when a human body is in the propagation path of the signal.The human body is comprised of molecules of water which are able to additionally absorb, diffract, scatter or reflect the energy of the radio signal [2]. Thus the presence of a human being in a wireless network path shows prominent strength changes at the receiving end. This particular phenomenon is being used in the proposed system by considering the Received Signal Strength of the Signals and thereby determining the presence of human subjects in the test environment.

In this review paper the flow is as follows: Section 2 contains the literature review followed by Section 3 which contains the review of three proposed systems [1], [2], [9].

\section{Literature Review}

Use of radio signals to detect the presence of humans is not a new field and various papers have been published on this topic. In the paper published by Bojan Mrazovac et all in 2012[2] it has been discussed how the irregularities of the received signal strength can be used to determine human presence. In 2006Ploetner and Trivedi [3] have combined the use of wireless sensor networks and other technologies like video cameras and even microphones to detect human presence. Daniel L. Silver et all have discussed the possibility of using the variation in the Received Signal Strength Indicator (RSSI) and Link Quality Indicator (LQI) values for intrusion detection and have also determined and tested an algorithm for detecting and intruder [4].

Another issue that can be encountered during the usage is that of false alarms. As stated by Lee, P.W.Q. et all in 2010[8] it is quite difficult to detect a human being by just setting a common threshold in the given environment. The fluctuation of the used radio signals gives a relevant solution. They[8] have proposed an algorithm which can be used for motion detection. This algorithm measures the fluctuations over a window of $\mathrm{X}$ packets. There is human detection if the percentage of fluctuations fall below the set threshold.

\section{Intrusion Detection}

a) Using ZigBee motes or Wi-Fi NIC:

In the proposed system[1] actual ZigBee motes were used instead of signal generators and spectrum analysers in order to demonstrate the feasibility of using these motes practically in characterizing the signal behaviour. The iris motes operate at a frequency around $2.4 \mathrm{GHz}$. Any type of Iris mote can function as a base station when it is connected to a programmable board MIB520. The role of MIB520 is to act as an interface for both programming individual motes and for data communication from base station to PC. The board runs on TinyOS, a free and open source component based embedded operating system and platform targeting WSNs that is written in the NesC programming language. The Arduino Uno microcontroller board is connected to the computer to switch on/off appliances. 


\section{International Journal of Science and Research (IJSR) \\ ISSN (Online): 2319-7064 \\ Index Copernicus Value (2013): 6.14 | Impact Factor (2014): 5.611}

Wi-Fi Network Interface Card, more commonly referred to as NIC, is a circuit board or card that was introduced on the PC so it can be connected to the Wi-Fi network. It provides common Internet connection means in office environment among other networking services and hardly any office lacks a Wi-Fi connection nowadays. The Internet connection is made free over Wi-Fi sometimes. The Arduino Uno microcontroller board engine is the ATMEL processor ATmega328 with interfacing slots. It can be connected to a computer using a USB cable and be powered by AC power adapter or DC batteries. Fig. 1 shown below indicates the connection between the microcontroller board (Arduino Uno) and the NIC card in the computer PC.

The data generated by this proposed system checks the various irregularities that have been generated and calculates the mean and the standard deviation. When the presence of human subjects in the testing environment is detected then the standard deviation and mean are greater.

They sampling rate should always be higher than the passing intruder so as to detect him other they can be missed and the intruder won 't be detected.

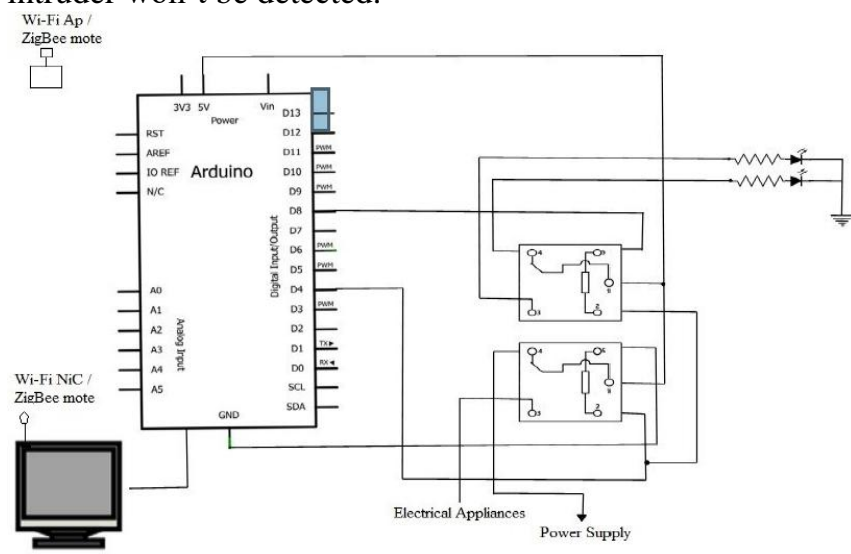

Figure 1: Schematic diagram for Wi-Fi or ZigBee System setup [1]

The proposed system [1] follows the following algorithm:

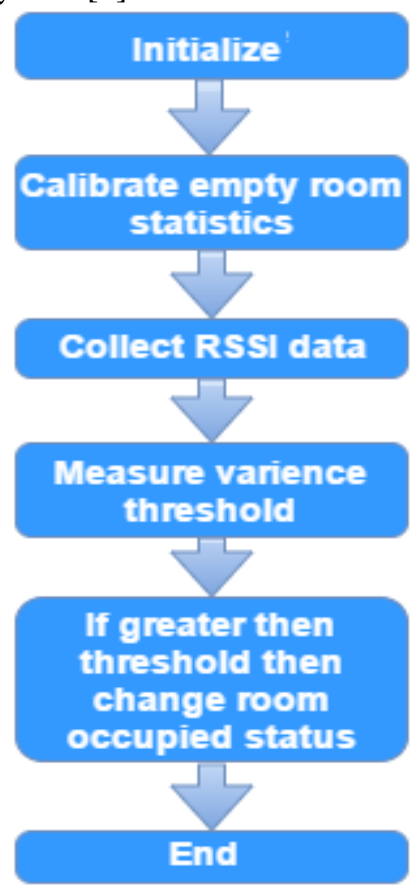

b) Using multiple receivers and discriminant analysis to detect number of human subjects:

Another system proposed by Lin, W.C. et all in 2011[9] uses RSSI to measure the presence of multiple human beings present in the given environment at the same time. They have stated that the fluctuation in the RSSI is more when more than one person is present in the testing area. They have also proposed a system which uses one transmitter and multiple receivers so as to minimize the number of false alarms generated and to increase the accuracy of the data generated in case one receiver fails to generate an output even when a human is present. They have stated the use of Discriminant analysis to distinguish between two or more groups and detect more than one human subjects present in the testing environment. Discriminant analysis is used to characterize or separate two or more groups of objects or events, in this case the presence of human subjects.

\section{Discriminant Analysis}

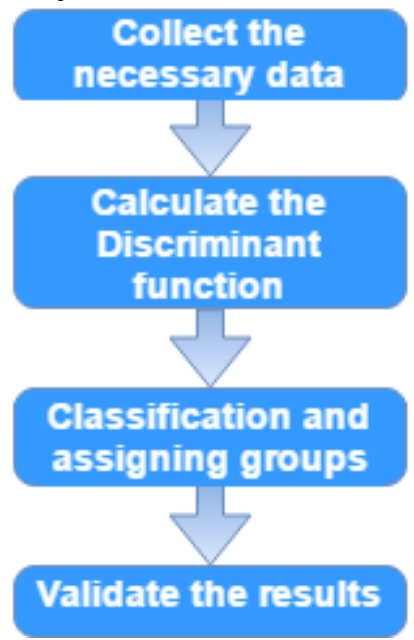

c) Using PCA for accurate detection of human subjects In the system proposed by B. Mrazovac et all in 2012[2] they have proposed the use of Principal Component Analysis(PCA) to obtain a more accurate result for detecting presence of humans rather than using standard deviation. However, they have stated that PCA requires more number of samples and thus increases the processing time of the system. They have suggested and incremental method for processing in future systems. 


\section{International Journal of Science and Research (IJSR) ISSN (Online): 2319-7064}

Index Copernicus Value (2013): 6.14 | Impact Factor (2014): 5.611

Thus the systems can be summarized as:

\begin{tabular}{|c|c|c|c|}
\hline Number & Author & Proposed System & Drawbacks \\
\hline 1 & $\begin{array}{c}\text { Mohamed Hadi Habaebi, Mahamat Mahamat } \\
\text { Ali, M.M. Hassan, M.S. Shoib, A.A.Zahrudin, } \\
\text { A.A. Kamarulzaman, W.S. Wan Azhan, Md. } \\
\text { Rafiqul Islam (2015)[1] }\end{array}$ & $\begin{array}{c}\text { Intrusion detection using ZigBee/Wi-Fi RF } \\
\text { signals. Used Standard Deviation and mean for } \\
\text { generating output. }\end{array}$ & $\begin{array}{c}\text { Less accurate due to the use of } \\
\text { standard deviation and mean. } \\
\text { Cannot detect the number of people } \\
\text { present. }\end{array}$ \\
\hline Number & $\begin{array}{c}\text { Author } \\
\text { Din, W.C., Seah, W.K.G. and Li, W. (2011) [9] }\end{array}$ & $\begin{array}{c}\text { Using Discriminant Analysis for detecting } \\
\text { more than one human subjects in the testing } \\
\text { environment. }\end{array}$ & $\begin{array}{c}\text { Some false alarms regarding } \\
\text { detection of multiple human } \\
\text { subjects }\end{array}$ \\
\hline 3 & $\begin{array}{c}\text { B. Mrazovac, M. Z. Bjelica, D. Kukolj, B. M. M. } \\
\text { Todorovic and S. Vukosavljev(2012)[2] }\end{array}$ & $\begin{array}{c}\text { System using Principal component analysis for } \\
\text { more accurate result for human detection. }\end{array}$ & $\begin{array}{c}\text { Requires a high processing time } \\
\text { because of the large amount of data. }\end{array}$ \\
\hline
\end{tabular}

\section{d) Future Scope}

After considering all three systems proposed by the authors [1], [2], [9] it can be observed that the system proposed by B. Mrazovac et all in 2012[2] is by far the most accurate system to be used for intrusion detection. Also some further modification can be done to these systems by adding an Arduino microcontroller or a Raspberry Pi to the system so that the system can upload the generated data to a certain website or Android application or send a SMS about the intrusion detection to the owner. This will make sure that the owner gets to know about the intrusions soon as the intruder is detected. The systems proposed can be used for either security purposes and energy management. However, I feel that the use of the system is more suitable for security purposes as there are various systems present for energy management.

\section{Conclusion}

Intrusion detection is an important criterion that everyone has to consider in the current age in which security is one of the highest priority of any person. The system discussed in this paper is one such alternative for security measures to be used in a small office or home office environment. Although there are some shortcomings these can be overcome by doing further research on this topic. The systems that have been discussed can be modified further after more research and could be used on a wide scale for security purposes and also for energy management. Thus we can say that the use of Wi-Fi signals or ZigBee signals for intrusion detection is quite feasible and should be further studied for better implementation. Considering all the data that has been reviewed a good fail safe system is yet to be made and there is still a lot of scope for research to be done.

\section{References}

[1] Mohamed Hadi Habaebi, Mahamat Mahamat Ali, M.M. Hassan, M.S. Shoib, A.A.Zahrudin, A.A. Kamarulzaman, W.S. Wan Azhan, Md. Rafiqul Islam "Development of Physical Intrusion Detection System Using Wi-Fi /ZigBee RF Signals" Procedia Computer Science 76 (2015) 547 552

[2] B. Mrazovac, M. Z. Bjelica, D. Kukolj, B. M. Todorovic and S. Vukosavljev, "System Design for Passive Human Detection using Principal Components of the Signal Strength Space," in IEEE 19th International Conference and Workshops on Engineering ofComputer Based Systems (ECBS), Novi Sad, Serbia, April 2012, pp. 164172.
[3] J. Ploetner and M. M. Trivedi, "A multimodal approach for dynamic event capture of vehicles and pedestrians," Proceedings of the 4th ACM international workshop on Video surveillance and sensor networks, pp. 203210,(2006).

[4] S. Hussain, R. Peters and D. L. Silver, "Using received signal strength variation for surveillance in residential areas", Proc. SPIE 6973, Data Mining, Intrusion Detection, Information Assurance, and Data Networks Security, 2008

[5] A. Luttwak, "Human Motion Tracking and Orientation Estimation using inertial sensors and RSSI measurements", December 2011.

[6] J. Perez, F. Seco, V. Milanes, A. Jimenez, J. C. Diaz and T. de Pedro, "An RFID-Based Intelligent Vehicle Speed Controller Using Active Traffic Signals,", Sensors 2010, 10, 5872-5887.

[7] M. Quwaider and S. Biswas, "Body Posture Identification using Hidden Markov Model with a Wearable Sensor Network," inProceedings of the ICST 3rd International conference on Body Area Networks, Brussels, Belgium, Belgium, 2008.

[8] Lee, P.W.Q., Seah, W.K.G., Tan, H.P. and Yao, Z.X.: Wireless Sensing without Sensors - An experimental study of motion/intrusion detection using RF irregularity. Journal of Measurement Science and Technology, Special Issue on Wireless Sensor Networks: Designing for real-world deployment and deployment experiences, Vol. 21, No. 12, (2010)

[9] Lin, W.C., Seah, W.K.G. and Li, W.: Exploiting radio irregularity in the internet of things for automated people counting. In Proc. of the 22nd IEEE Symposium on Personal, Indoor, Mobile and Radio Comm. (PIMRC „11), Toronto Canada, (2011)

[10] Mrazovac, B., Bjelica, M.Z., Kukolj, D., Todorovic, B.M. and Samardzija, D.: A Human Detection Method for Residential Smart Energy Systems Based on Zigbee RSSI Changes. IEEE Transactions on Consumer Electronics, vol.58, no.3, pp. 819-824. (2012)

[11] Smith, L.I.: A tutorial on Principal Components Analysis. (2002). [Online]. Available: http://www.sccg.sk/ haladova/principal_components.pdf (May 2012)

[12] Shlens, J.: A tutorial on Principal Component Analysis: Derivation, Discussion and Singular Value Decomposition. (2003). Available: http://www.cs.princeton.edu/ picasso/mats/PCA-Tutorial-Intuition_jp.pdf (May 2012)

[13] M. Nakatsuka, H. Iwatani, and J. Katto, "A study on passive crowd density estimation using wireless sensors," in Proceedings of $4^{\text {th }}$ International Conference on Mobile Computing and Ubiquitous Networking (ICMU), Tokyo, Japan, 11-13 June 2008 